\title{
Elephant poaching in Niassa Reserve, Mozambique: population impact revealed by combined survey trends for live elephants and carcasses
}

\author{
Vernon R. Booth and KeVin M. Dunham
}

\begin{abstract}
Trends in the populations of large herbivores in Niassa Reserve, Mozambique, have been monitored through biennial aerial surveys since 1998. The elephant Loxodonta africana population has been subjected to intensive illegal hunting since 2006 . We used a simple population model to mimic the observed trends in the numbers of live and dead elephants to demonstrate the impact of poaching. The number of fresh or recent carcasses recorded was used in the model as an index of the annual mortality rate. A maximum likelihood analysis to compare population models revealed that the best fit to the survey estimates of both live elephants and old or very old carcasses was a model that started with 6,635 elephants in 1987 . This number increased through births by $4.6 \%$ annually and decreased through deaths from natural and anthropogenic causes. In the best-fit model, the mean mortality rate in any year was 3.2 times the observed $1+2$ carcass ratio (ratio for carcasses in age categories 1 and 2), and carcasses remained visible for a mean of 6 years. The model suggested that c. 900 elephants were poached during 2007-2010 and another c. 1,00o during 2011. Population estimates for live elephants and carcasses are now routine outcomes of aerial surveys conducted as part of the CITES programme for Monitoring the Illegal Killing of Elephants, and our method can be applied to any population with a time series of estimates for live and dead elephants.
\end{abstract}

Keywords Aerial survey, carcass, elephant, Mozambique, Niassa, poaching, population model, population trend

This paper contains supplementary material that can be found online at http://journals.cambridge.org

\section{Introduction}

7 here have been notable increases in both the poaching of African elephants Loxodonta africana and the illegal trade in ivory since 2007, mainly because of the rising demand for ivory in the fast-growing economies of Asia,

VeRnON R. BоOTH (Corresponding author) 9 Glenara Avenue North, Highlands, Harare, Zimbabwe. E-mail vernonrbooth@gmail.com

Kevin M. Dunham PO Box CH385, Chisipite, Harare, Zimbabwe

Received 8 May 2014. Revision requested 26 June 2014.

Accepted 17 July 2014. First published online 15 October 2014. particularly China and Thailand (UNEP et al., 2013). Elephant populations in Eastern and Southern Africa that were regarded as secure are now threatened, as a wave of poaching seems to be spreading east and southwards across Africa. The Monitoring the Illegal Killing of Elephants (MIKE) programme (CITES, 2004) collects data on elephant poaching and law enforcement from $>_{50}$ sites across Africa (Burn et al., 2011). However, this programme depends on the law enforcement authority at each site collecting and reporting the carcass data used to judge the effectiveness of their law enforcement. Aerial surveys can provide both an independent check and an assessment of elephant population trends over a large area. The MIKE standards for aerial surveys of elephant populations (Craig, 2012) require the collection of data on both live elephants and elephant carcasses.

Douglas-Hamilton \& Hillman (1981) were among the first to draw attention to the importance of carcass number as an indication of the trend in a population of live elephants. Later, Douglas-Hamilton \& Burrill (1991) showed that the proportion of dead elephants was correlated with the percentage change in the number of live elephants during the previous 4 years. Wells (1989) modelled a theoretical elephant population under different mortality regimes. $\mathrm{He}$ suggested that temporal patterns in the number of dead elephants (as a proportion of live plus dead elephants) permitted natural mortality alone to be distinguished from mortality from both hunting and natural causes, and for selective hunting to be distinguished from unselective hunting.

Here we describe a method that uses a simple population model to reveal the trend in an elephant population by combining survey estimates for live elephants with survey estimates for elephant carcasses. A previous model of an elephant population (Dunham, 2008) is extended, firstly by varying the annual mortality rate in the model to reflect the observed variation in the number of fresh or recent carcasses of elephants, and secondly by mimicking the observed variations in both the number of live elephants and the number of old or very old carcasses. We illustrate the method using long-term aerial survey data for the savannah elephant population in the Niassa National Reserve in northern Mozambique.

The Niassa population is the largest elephant population in Mozambique and the only one that has been surveyed regularly in recent years. The trend in the estimated number 
of live elephants in the Reserve has not been clear (Craig, 2011), however, with the sample survey estimates suggesting that the number of live elephants increased from c. 12,000 during 2006 to c. 20,000 during 2009 , before declining to c. 12,000 during 2011 (Table 1). Real changes of this magnitude over just a few years are unlikely. However, it is not unusual for the trend in population number to be unclear, especially if the population estimates are derived from a relatively small number of sample surveys. We determine the likely trend in the Niassa elephant population by using a model that mimics both the number of live elephants and the number of carcasses. In the process, our analysis reveals the recent impact of illegal hunting on the elephant population.

\section{Study area}

Niassa National Reserve (c. $42,000 \mathrm{~km}^{2}$ ) is in northernmost Mozambique, covering part of Cabo Delgado Province and nearly one-third of Niassa Province (Fig. 1). It is the country's largest conservation area and the third largest protected area in Africa, and has the highest concentration of wildlife in Mozambique. Tanzania's Selous Game Reserve (c. 50,000 $\mathrm{km}^{2}$ ) lies $160 \mathrm{~km}$ north of the Rovuma River, which forms the international border as well as the northern border of Niassa National Reserve. Approximately 9,000 $\mathrm{km}^{2}$ of communal land in southern Tanzania, lying between the Niassa and Selous reserves, is designated the SelousNiassa Corridor (Baldus \& Hahn, 2009). Niassa has a tropical climate, with mean monthly temperatures of c. $30^{\circ} \mathrm{C}$ during October and November, falling to c. $20{ }^{\circ} \mathrm{C}$ during the cold season (June-August). Rainfall is restricted to the hot season, beginning in late October and ending during April or May. Altitude is lowest in the east $(200 \mathrm{~m})$ at the confluence of the Rovuma and Lugenda Rivers, where mean annual rainfall is c. $900 \mathrm{~mm}$. The ground rises steadily to $1,400 \mathrm{~m}$ in the west, where annual rainfall is c. $1,500 \mathrm{~mm}$.

The Reserve is noted for spectacular granite inselbergs that stand above the surrounding landscape. Drainage is dominated by the Rovuma and Lugenda Rivers, which are large, braided, sand rivers with strong perennial flows. A central watershed between these rivers feeds an extensive network of seasonally inundated wetlands or dambos as well as numerous seasonal rivers lined with dense riparian woodland. Most of the Reserve is covered by miombo (Brachystegia) woodland interspersed with drier areas of bushed savannah. Fires started deliberately by people, and fuelled by $2 \mathrm{~m}$ high grass, burn annually during the late dry season (August-October; Ribeiro et al., 2008).

Niassa National Reserve was created in 1954 but abandoned after hostilities started in 1975. After the 1992 national peace accord the Government of Mozambique entered into an arrangement with a private company to manage

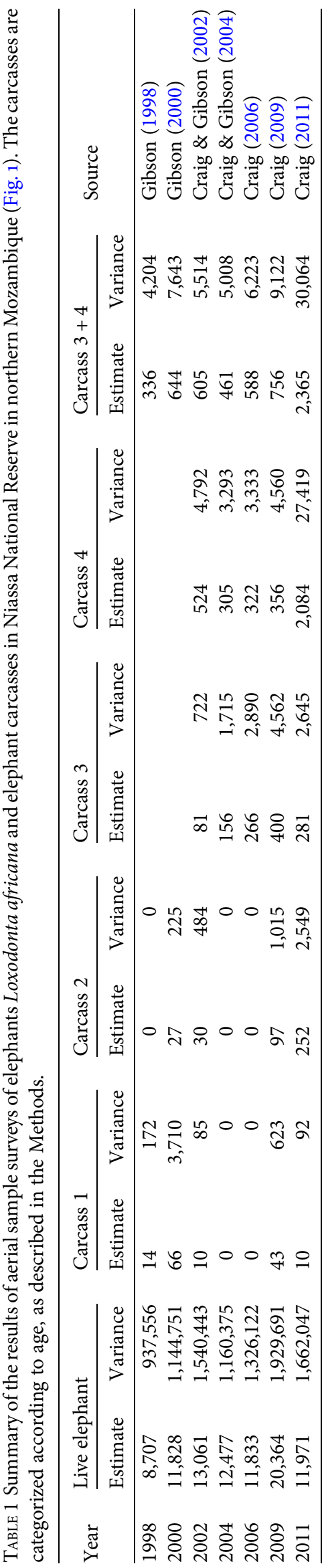




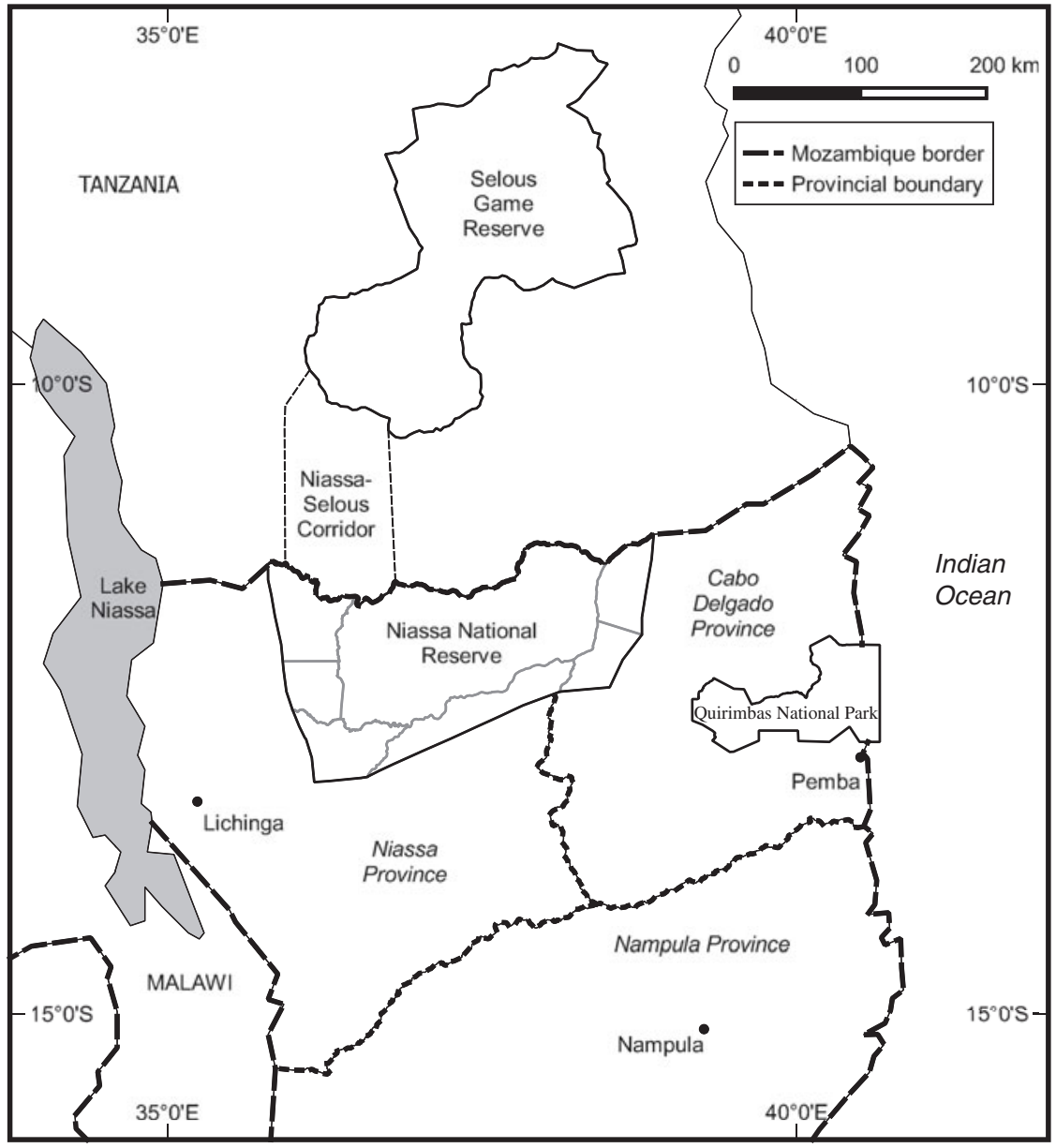

FIg. 1 The location of Niassa National Reserve in northern Mozambique. the Reserve. Established during 1998, the Sociedade para a Gestão e Desenvolvimento da Reserva do Niassa (SGDRN) was an innovative partnership between the public and private sectors, with the Government of Mozambique retaining ownership of $51 \%$ while providing SGDRN with exclusive management and development rights. During the last 10 years SGDRN undertook basic research and developed the Reserve by securing private investment in tourism.

The 2007-2012 management plan divided the Reserve into 17 management units: nine hunting blocks, six phototourism blocks and two zones of high biodiversity value (SGDRN, 2006). The presence within the Reserve of nine administrative districts, three towns and $>40$ villages, which support $>35,000$ people, introduced an unusual dimension to management of the Reserve. The livelihoods of these communities are centred on crop production, with shifting agriculture being the norm. These communities face considerable challenges in terms of their remoteness, limited access to physical and social infrastructure, and widespread poverty; meanwhile continued clearing of natural vegetation for agriculture is a significant threat to the conservation goals of Niassa (Cunliffe et al., 2009; Mandondo \& Ngarivhume, 2009).
Niassa is a study site for the MIKE programme (CITES, 2004). Each year 2-4 elephant bulls are shot legally by sport hunters in the Reserve. In addition, 2-6 elephants are shot annually during problem-animal control (Marufo et al., 2009). To the south and east of the Reserve lie communally occupied areas that still support wildlife, including elephants, but for which there are no formal management arrangements or plans.

\section{Methods}

\section{Aerial surveys of wildlife}

Stratified systematic transect sampling of the wildlife in Niassa National Reserve was undertaken during 1998, 2000, 2002, 2004, 2006, 2009 and 2011 (Gibson, 1998, 2000; Craig \& Gibson, 2002, 2004; Craig, 2006, 2009, 2011) using the methods described by Norton-Griffiths (1978). One light aircraft (Cessna 185 or 206) equipped with a radar altimeter and a Global Positioning System (GPS) receiver was used for each survey. The surveys were conducted during October-November and took c. 20 days to cover the $42,200 \mathrm{~km}^{2}$ study area. The location of the first transect 
in each stratum was determined randomly. Maps of the strata boundaries and transects were uploaded to a portable GPS and used for accurate navigation along transects. A nominal height of $300 \mathrm{ft}(91 \mathrm{~m})$ above ground level was maintained using the radar altimeter.

The boundaries of search strips on each side of the aircraft were defined by pairs of rods attached to the aircraft lift struts. The width of the strips was measured empirically by flying at various heights at right angles across an airstrip on which large-sized numbers had been painted at $10 \mathrm{~m}$ intervals. Each observer called out the outermost and innermost numbers seen within his strip. The rods were adjusted so that the difference between the numbers set the calibrated strip width at c. $200 \mathrm{~m}$ on each side when at a height of $300 \mathrm{ft}$. The nominal sampling intensity was c. $10 \%$ but the mean sampling intensity was $9.7 \%(n=7$, range 7.9-10.6).

To achieve a search rate of $\mathrm{c} .1$ minute per $\mathrm{km}^{2}$ the aircraft was flown along transects at $\leqslant 185 \mathrm{~km}$ per hour. Two experienced observers seated behind the pilot and recorder called out sightings of animals within the search strips. The recorder, seated next to the pilot, recorded these sightings of animals and carcasses, noting the species, number and location in degrees and decimal minutes from a second GPS. The height as indicated by the radar altimeter was noted at 30-s intervals, to allow the calculation of the mean height for each transect. The time at which the flights along each transect started and ended was also recorded to provide mean speed.

\section{Elephant carcasses}

The observers noted the approximate time since death for each elephant carcass and allocated each carcass to an age category. During 1998-2000 three categories were used: 1, fresh; 2, recent; 3, old (Douglas-Hamilton \& Hillman, 1981). Since 2002 the previous category 3 has been replaced with a new category 3 representing old carcasses and a new category 4 for very old carcasses. The new categorization is that recommended for elephant surveys in MIKE sites (Craig, 2012). Generally, carcasses in categories 1 and 2 were of elephants that had died during the year of the survey (mostly since the end of the rainy season) and carcasses in categories 3 and 4 were of elephants that had died during earlier years or possibly during the previous rainy season.

The survey reports gave the carcass ratio sensu Douglas-Hamilton \& Burrill (1991; although it is actually a proportion or percentage, not a ratio), which was the estimated number of all elephant carcasses expressed as a percentage of the estimated number of all elephants (i.e. alive plus dead). This all-carcass ratio is an index of the elephant mortality rate during the several years prior to the survey. We calculated the carcass ratio for categories $1+2$, which is an index of the elephant mortality rate during the year of the survey (including all causes, both natural and anthropogenic). The carcass ratio for categories $1+2$ is defined as the estimated number of elephant carcasses in age category 1 or 2, expressed as a percentage of the sum of this number and the estimated number of live elephants.

\section{Data analysis}

The population estimates and variances that we extracted from the survey reports had been calculated using method 2 of Jolly (1969). We calculated the $95 \%$ confidence limits for all mean estimates of population number as: population estimate $\pm\left(t_{v} \cdot \sqrt{ }\right.$ total variance $)$, where $t=$ student's $t$, and $v=$ degrees of freedom estimated by Satterthwaite's rule (Snedecor \& Cochran, 1980; Gasaway et al., 1986). If, for any survey, the calculated lower confidence limit was less than the number of individuals seen in the search strips, this latter number was substituted for the lower confidence limit.

Trends in elephant number were determined assuming that an exponential model was appropriate for estimating the rate of population change. The exponential rate of population change per annum $(r)$ was calculated using the method of Gasaway et al. (1986) based on weighted regression of natural logarithms of the population estimates against time, with the variance of $r$ based on the sampling variances of the population estimates. The percentage rate of population change per annum was $100 \times\left(\mathrm{e}^{r}-1\right)$. The population was considered to have increased significantly over a time period if both lower and upper $95 \%$ confidence limits of $r$ were positive.

\section{Population model}

The numbers of live elephants and elephant carcasses in Niassa were mimicked with a model that started with an assumed population number. The number of elephants during the following year was then determined by increasing the starting population by an assumed birth rate and decreasing it by an assumed mortality rate. Thus:

$$
N_{t}=(1+b) \cdot\left(1-m_{t-1}\right) \cdot N_{t-1}
$$

where $N_{t}=$ number of elephants in year $t ; b=$ mean birth rate of population per year (i.e. the mean proportion of elephants in the population that produce a calf during the year), assumed to be constant; and $m_{t-1}=$ mean mortality rate of elephants of both sexes and all ages, as a proportion of the population, in year $t-1$. Consequently, $\left(m_{t-1} . N_{t-1}\right)$ is the number of elephants that died during year $t-1$ and this number is included in the equation to determine the number of elephant carcasses (see below).

The $1+2$ carcass ratio provides an index of the mortality rate during the survey year. Carcasses in age categories 1 and 2 have most of the skin still present. Hence for surveys conducted at the end of the dry season most if not all elephants in carcass categories 1 and 2 had probably died since the end of the 
last rains, because the skin would have decomposed during the wet season. The carcasses of some elephants that died after the rains may have lost their skins and thus been included in category 3 or, if the bones were scattered, category 4 . Thus, whereas most (if not all) category 1 and 2 carcasses were of elephants that died after the rains, perhaps not all elephants that died during the survey year were in categories 1 or 2 .

The number of live elephants plus the number of category $1+2$ carcasses is the number of elephants that were alive at the end of the rainy season. The number of these that had died by the time of the late dry-season survey was the number of category $1+2$ carcasses. No category 1 or 2 carcasses were seen during the 2004 or 2006 surveys (Table 1) but, given the large size of the population, some elephants must have died during these years and so the zero estimates probably represent sampling error. During 1998, 2000 and 2002 the lower confidence limit of the estimated number of category 1 or 2 carcasses was close to zero and therefore similar to the zero estimates of 2004 and 2006. Hence, we assume that the mortality rate was low during these years and that the best estimate of mortality rate was provided by the mean of the values for the $1+2$ carcass ratio from the five surveys during 1998-2006. Both the mortality rate and the number of elephants dying increased dramatically during the period after the 2006 survey.

In the model population, the mortality rate was calculated as

$$
m_{t}=f \cdot[1+2 \text { carcass ratio }]_{t} / 100
$$

where $f=$ constant, in effect a correction factor to allow for the fact that the carcasses of elephants that died during the rainy season early in the year might have lost their skin and thus be considered category 3 carcasses.

Category 3 and 4 carcasses remain for several years until the bones decompose or are scattered such that the carcasses are no longer recognizable to aerial observers. It is not known for how many years elephant carcasses remain recognizable and so this period is the fourth unknown to be included in the model: $c$ is defined as the mean duration of the time period (in years) between the death of an elephant and the disappearance of its carcass. Hence, the number of carcasses in any year is the sum of the numbers of elephants that died during the last $c$ years.

In the model, the number of category $3+4$ carcasses was calculated as the total number of elephants that died during the last $c$ years (i.e. the current year and $c \times 1$ previous years) minus the number of elephants that died during the current year and the carcasses of which are still at the category 1 or 2 stage. Thus,

$$
\begin{aligned}
D_{t}= & {\left[\left(m_{t} \cdot N_{t}\right)+\left(m_{t-1} \cdot N_{t-1}\right)+\left(m_{t-2} \cdot N_{t-2}\right)\right.} \\
& \left.+\left(m_{t-3} \cdot N_{t-3}\right) \ldots+\left(m_{t-(c-1)} \cdot N_{t-(c-1)}\right)\right] \\
& -\left[N_{t} \cdot(1+2 \text { carcass ratio })_{t} / 100\right]
\end{aligned}
$$

where $D_{t}=$ number of category $3+4$ carcasses present in year $t$.

The numbers of both live elephants and carcasses predicted by the model were compared to the survey estimates of elephant and carcass numbers, using Martin's (1992) maximum likelihood estimator (Dunham, 2008). For each year during which a population was surveyed the analysis compares the population number predicted by the model to the survey estimate. It does this by relating the difference between the predicted and estimated numbers to the variance of the mean estimate of population. The outcome of this analysis is an estimator that equals one if the predicted and estimated numbers are identical during all survey years, and declines towards zero the less perfect the fit between the predicted and estimated numbers. When several models are compared, the one that gives the greatest index value is the model that provides the best fit to the survey estimates.

The model was run for 1987-2011. The start year was 1987 to calculate the number of elephants that died during the 10 years preceding the 1998 survey. The Microsoft Excel 2010 add-in Solver was used to determine the values of the starting population during $1987\left(N_{1987}\right)$ and the constants $b$ (mean birth rate), $f$ (factor relating $1+2$ carcass ratio to mortality rate) and $c$ (mean number of years that carcasses remain recognizable) that maximized the index value. Executing Solver was equivalent to running a series of models with different combinations of $N_{1987}, b, f$ and c. In the model the $1+2$ carcass ratio was taken as 0.25 (the mean observed ratio during the 1998-2006 surveys) until 2007, after which it increased at an exponential rate of 0.539 annually (as calculated from a value of 0.25 during 2007 and the observed values during 2009 and 2011).

Preliminary analyses with the evolutionary solving method in Solver revealed that Solver would run only with constraints attached to the four unknowns in the model. For each unknown we deliberately selected minimum and maximum values that were outside the range of values that we considered likely for the Niassa population. We reasoned that this would allow Solver to run but would have little influence on its final choice of the best-fit values for the unknowns. The unknowns in the model were constrained as follows: $N_{1987}$ as an integer, 100-10,000; $b, 0-0.25 ; f$, 0.520; and $c$ as an integer, 1-10.

The initial starting values of the unknowns were varied, with three possible starting values for each unknown: the value of the minimum constraint, the value of the maximum constraint, and the mean of these two values. Hence, the possible starting values for $N_{1987}$ were 100, 5,050 and 10,000; for $b$ were $0,0.125$ and 0.25 ; for $f$ were $0.5,10.25$ and 20; and for $c$ were 1, 5 and 10. Thus, there were 81 combinations of starting values and we ran Solver for each combination (scenario). For non-smooth optimization problems, Solver's evolutionary solving method uses algorithms to seek a 'good' solution, not a solution that can be 
proved to be optimal (Frontline Systems, 2014). The evolutionary solving method differs from classical optimization methods in several ways, including its use of random sampling. Consequently, it may yield different solutions on different runs.

Approximately $50 \%$ (40/81) of the scenarios produced the same best-fit values for the unknowns, regardless of the starting values (Supplementary Table S2). Another $20 \%$ of scenarios produced similar best-fit values (e.g. $N_{1987}$ predicted to be $6,634,6,636$ or 6,637 instead of 6,635$)$. Solver runs that predicted very different values were always a poorer fit to the survey estimates (as shown by very small index values) and these scenarios were rerun, sometimes more than once. The analysis revealed that the variation in the best-fit values between the first run for each scenario was not attributable to the starting values for the unknowns but was probably a result of the random element involved in Solver's evolutionary solving method.

The modelling exercise was repeated to determine the values for $N_{1987}, b$ and $f$ that produced a trend that was the best fit to the observed numbers of live elephants only. The fit between the modelled and observed numbers of carcasses was noted but no attempt was made to fit the modelled trend to the observed numbers.

\section{Rainfall}

Temporal trends in annual rainfall over the Reserve were determined using the African rainfall estimation algorithm (Herman et al., 1997), which provides satellite-derived and rain-gauge-coupled rainfall estimates for southern Africa. Decadal data for July 1997-June 2011 inclusive were downloaded from the Famine Early Warning System website (FEWS NET, 2014) and summed to provide rainfall estimates for each July-June climate year. For each climate year, mean rainfall was calculated for the 665 pixels of $8 \times 8 \mathrm{~km}$ that covered Niassa National Reserve.

Fire

Interannual variation in the proportion of the Reserve that was burnt during survey years was determined using MODIS (Moderate Resolution Imaging Spectroradiometer) burnt area data. For each survey year from 2000 we calculated the total area of all $500 \times 500 \mathrm{~m}$ pixels lying within the Reserve in which fires were recorded (i.e. pixels with a Quality Assessment of 1 or 2) during May-October inclusive, and hence the percentage of the Reserve that was burnt. MODIS data were not available for 1998. During 2002, 2004, 2006 and 2009 the percentage of the Reserve burnt was also recorded during aerial surveys of the wildlife (Craig \& Gibson, 2002, 2004; Craig, 2006, 2009). The percentage burnt during other survey years was not reported.
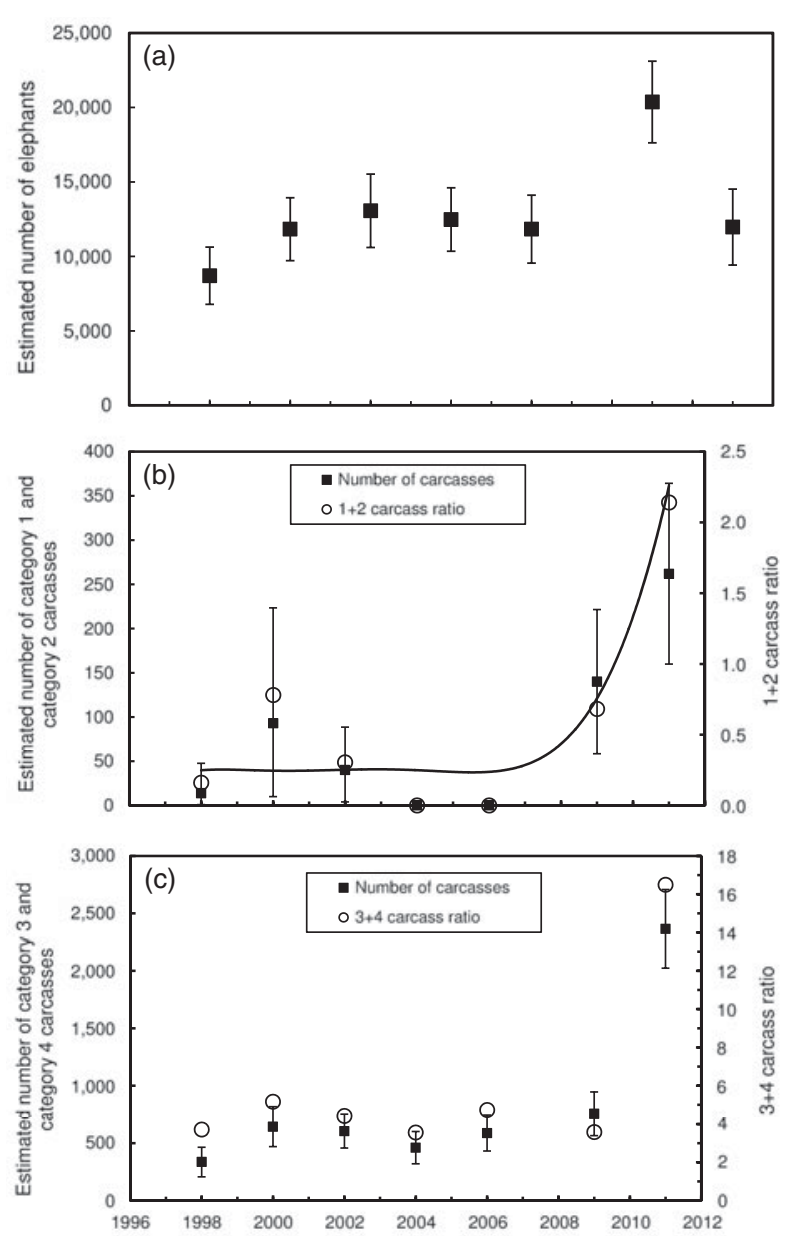

FIG. 2 (a) Number of live elephants Loxodonta africana, (b) number of elephant carcasses in age categories 1 and 2, and (c) number of elephant carcasses in age categories 3 and 4 , based on aerial sample surveys of Niassa National Reserve, Mozambique (Fig. 1) during 1996-2012. Vertical lines indicate 95\% confidence intervals of estimates. The solid line in (b) is the assumed trend line for the $1+2$ carcass ratio that was used in the population model. Data sources are provided in the text.

\section{Results}

The number of elephants estimated by the surveys varied from 8,707 during 1998 to 20,364 during 2009 (Fig. 2a, Table 1). The observed annual exponential rate of increase (r) was $0.063-6.49 \%$ (95\% CI $0.044-0.081$ ) during 19982009. However, the 2009 estimate was particularly high; when only the 1998-2006 data were considered, observed $r$ was $0.029-2.93 \%$ per annum (95\% CI $0.002-0.060$ ). That the lower confidence limit is just above zero suggests that $r$ may not be significantly different from zero. The number of fresh and recent elephant carcasses (age categories 1 and 2) estimated by the surveys increased sometime after 2006 (Fig. 2b) and the number of old and very old carcasses (age categories 3 and 4) more than tripled between 2009 and 2011 (Fig. 2c, Table 1). 

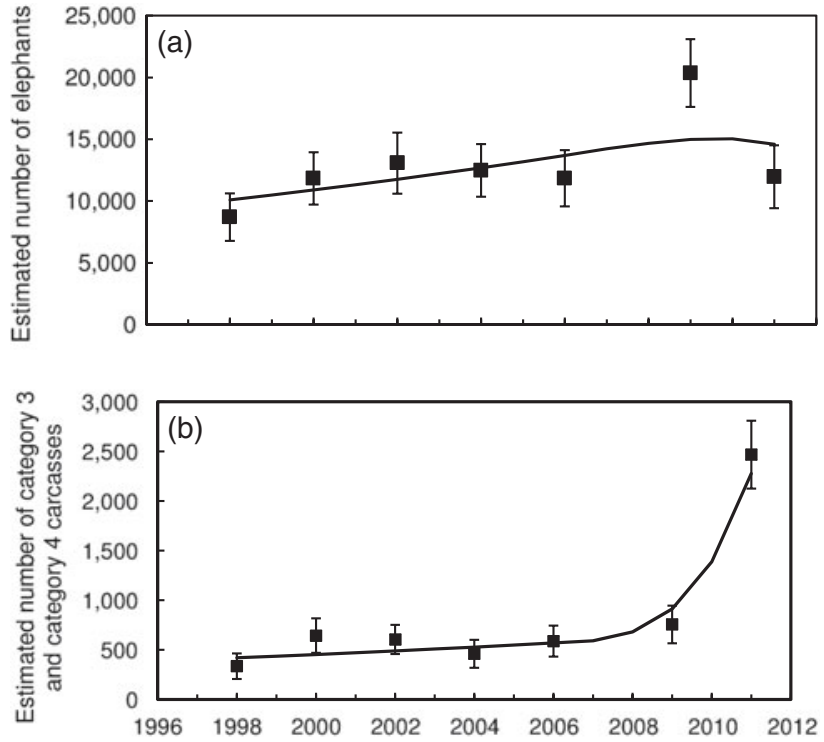

FIG. 3 Outputs of a model providing best fits to both the numbers of live elephants (a) and the numbers of elephant carcasses in age categories 3 and 4 (b). The modelled population initially comprised 6,635 elephants during 1987, which increased by births at $4.6 \%$ annually, and decreased at an annual mortality rate 3.2 times the $1+2$ carcass ratio (expressed as a proportion), with carcasses remaining visible for a mean of 6 years after death. Data points indicate numbers estimated during the surveys, with vertical lines indicating upper and lower 95\% confidence intervals of estimates. Sources for survey data are provided in the text.

The maximum likelihood analysis to compare population models for 1987-2011 revealed that the best fit to the observed elephant and carcass numbers was provided by a model population of 6,635 elephants during 1987 , which increased by births at $4.6 \%$ annually and decreased at an annual mortality rate that was 3.2 times the $1+2$ carcass ratio, with the carcasses of elephants remaining visible for a mean of 6 years after death (Fig. 3). Generally, there was little variation in these numbers, regardless of the starting values used when running Solver (Supplementary Table $\mathrm{S} 1$ ).

When the modelling exercise was repeated to find the model that provided a trend line that was the best fit to the observed number of live elephants only (ignoring the fit to carcass number), the model population started with 4,585 elephants during 1987 , increased by births at $9.1 \%$ annually and decreased at an annual mortality rate that was 11.3 times the $1+2$ carcass ratio (Supplementary Table S2). This trend line (Fig. 4a) was a better fit to live elephant numbers than the trend produced when fitting a model to both live elephants and carcasses (Fig. 3a) but it did not fit the observed number of carcasses, over-predicting them during 2009 and 2011, even if they remained visible for a mean of just 2 years after death (Fig. 4 b).

The trend of the modelled population that gave the best fit to the survey estimates of both elephant and carcass numbers is likely to be a reasonable representation of the trend
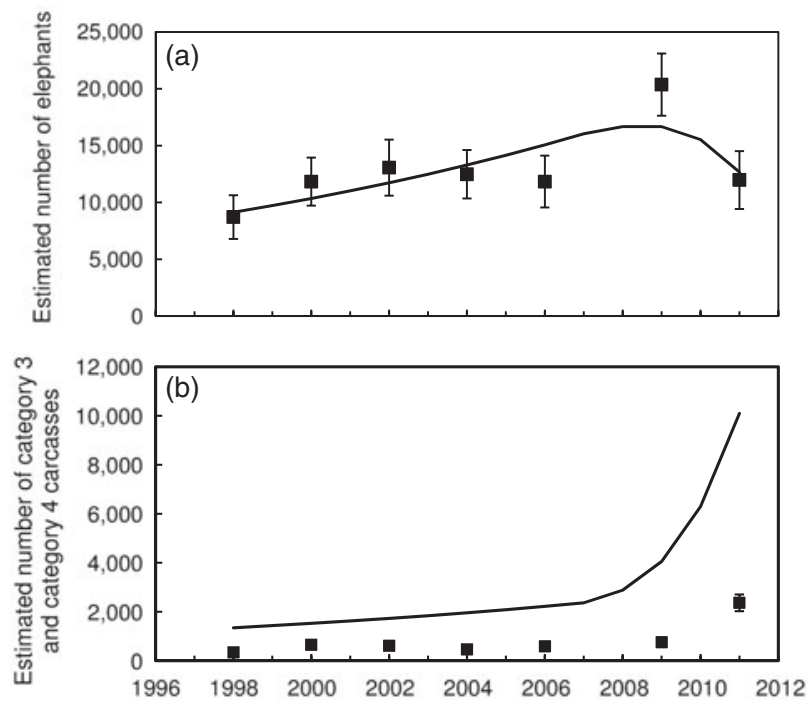

FIG. 4 Outputs of a model providing best fit only to the numbers of live elephants: (a) the number of live elephants; (b) the number of elephant carcasses in age categories 3 and 4 . The modelled population initially comprised 4,585 elephants during 1987 , which increased by births at $9.1 \%$ annually and decreased at an annual mortality rate 11.3 times the $1+2$ carcass ratio (expressed as a proportion). The trend line for carcasses assumes that the carcasses remained visible for a mean of only 2 years after death. Data points indicate numbers estimated during the surveys, with vertical lines indicating upper and lower $95 \%$ confidence intervals of estimates. Sources for survey data are provided in the text.

exhibited by the elephant population in Niassa since 1998 . This trend line suggested that the population increased during 1998-2009 but then levelled off or declined during 2009-2011, as the mortality rate increased dramatically after 2006. The population model suggested that the 2009 survey overestimated elephant number but not carcass number.

The surveys revealed a large increase in the mortality rate of elephants (as indexed by the $1+2$ carcass ratio) during 2006-2009 and this was reflected in an increase of c. 1,600 old or very old carcasses observed during 2011. In the model that provided the best fit to numbers of both live and dead elephants, 2,522 elephants died during 2007-2011. If the mortality rate had not increased sometime after 2006 the model suggests that just 621 would have died during these years, and therefore an additional 1,901 elephants died during 2007-2011 as a consequence of the increased mortality rate. This increase was exponential and the same model suggests that 1,010 of these additional deaths occurred during 2011.

Mean annual rainfall over the Reserve was $798 \mathrm{~mm}$ during 1997-2011 (Table 2). Rainfall was well below the mean during only 2 climate years (1997-1998, 429 mm; 19992000, $470 \mathrm{~mm}$ ). The MODIS burnt area product suggested the percentage of the Reserve burnt annually increased from 
TABLE 2 Mean rainfall in Niassa National Reserve (Fig. 1) for each climate year (July-June) from 1997-1998 to 2010-2011, determined using the African Rainfall Estimation algorithm (Herman et al., 1997).

\begin{tabular}{lc}
\hline Climate year & Mean estimated rainfall $(\mathrm{mm})$ \\
\hline $1997-1998$ & 429 \\
$1998-1999$ & 888 \\
$1999-2000$ & 470 \\
$2000-2001$ & 935 \\
$2001-2002$ & 779 \\
$2002-2003$ & 1,040 \\
$2003-2004$ & 807 \\
$2004-2005$ & 849 \\
$2005-2006$ & 643 \\
$2006-2007$ & 1,072 \\
$2007-2008$ & 791 \\
$2008-2009$ & 767 \\
$2009-2010$ & 838 \\
$2010-2011$ & 862 \\
Mean & 798 \\
\hline
\end{tabular}

TABLe 3 Percentage of the area of Niassa National Reserve (total area $42,277 \mathrm{~km}^{2}$; Fig. 1) burnt during May-October inclusive for years when aerial surveys of wildlife were carried out. Data for 2000-2011 were provided by the MODIS burnt area product (no MODIS data are available for 1998). The percentage of area burnt was also recorded during aerial surveys of wildlife during 2002-2009. Blank cells indicate the absence of data.

\begin{tabular}{lll}
\hline & \multicolumn{2}{l}{$\%$ area burnt } \\
\cline { 2 - 3 } Year & MODIS burnt area product & Aerial survey \\
\hline 1998 & & \\
2000 & 17.2 & 52 \\
2002 & 15.9 & 61 \\
2004 & 27.8 & 59 \\
2006 & 36.1 & 63 \\
2009 & 38.3 & \\
2011 & 33.4 & \\
\hline
\end{tabular}

$16-17 \%$ during $2000-2002$ to $>30 \%$ during 2006-2011 (Table 3). However, fires and burnt areas recorded during the aerial surveys of wildlife suggested that $50-60 \%$ of the Reserve burnt annually. It is beyond the scope of this work to explain the discrepancy between these two data sources but VRB's personal observations of the Reserve during the dry season are closer to the records from the aerial surveys.

\section{Discussion}

\section{Cause of increased mortality of elephants}

Increased mortality of African elephants and a subsequent population die-off often follow severe drought, as observed, for example, in Tsavo (Kenya) during 1970-1971 (Corfield, 1973). However, annual rainfall in Niassa was average or above-average after 2006 (Table 2), which suggests that the observed increase in mortality during that period was not drought-related. We considered the possibility that interannual variation in the percentage of the Reserve that was burnt influenced the visibility of elephant carcasses to aerial observers, but the increase in the number of carcasses recorded during 2011 could not be explained by an increase in the proportion of the Reserve that was burnt (Table 3 ). We believe that there is no natural explanation for the increased mortality observed after the 2006 survey but that it resulted from illegal hunting. Hence, it is likely that the additional 1,901 elephants that the models suggest died during 2007-2011 (including the additional 1,010 that died during 2011) were poached. The 2011 figure is equivalent to a mean of 2.8 elephants poached daily. Our estimate of 1,010 elephants poached during 2011 is much greater than the number of poached elephants (76) found by field staff and reported to the MIKE programme that year (CITES, 2012).

\section{Population model}

Our study is the first to model simultaneously the numbers of live and dead elephants and to match the modelled trends to survey estimates of elephant and carcass numbers. Application of this approach was facilitated by the consistency between years in survey design, execution and personnel during the Niassa survey programme. The importance of this approach is revealed by the model that mimicked the trend in the number of live elephants only. Although the fit between the modelled and observed elephant numbers (Fig. 4a) was better than the fit produced by the model that mimicked trends in both elephant and carcass numbers (Fig. 3a), the best-fit estimates for the unknown parameters were not realistic in the model that fit only live elephants, because they implied that only $9 \%$ of elephants that died were recorded as category 1 or 2 carcasses during a survey in the year that they died, and that elephant carcasses disappeared (at least to an aerial observer) within 2 years, on average. The population model assumes that the Niassa elephant population is essentially a closed population, with no large-scale movements of elephants between the Reserve and surrounding areas. Radio-tracking studies of elephants in the SelousNiassa corridor have revealed that individuals living close to the Rovuma River (the international border) cross the river, moving between Mozambique and Tanzania, because their home range spans the border (Hofer \& Mpanduji, 2004). There is no evidence of large numbers of elephants moving between Niassa and Selous Reserves. Similarly, tracking of collared elephants in the communal lands south-east of Niassa, and in Quirimbas National Park to the east, show 
that the elephants remain there and do not move to and from Niassa (van Aarde et al., 2009).

Our model suggests that the number of elephants dying in any year is 3.2 times greater than the estimated number of fresh and recent carcasses. The presence (age category 2) or absence (category 3 ) of the skin is the most easily observed difference between these age categories. Hence, it seems likely that, at least in Niassa, the skin of dead elephants decomposes in $<_{1}$ year, particularly for elephants that die during the rainy season.

\section{Conservation and management implications}

Population estimates for live elephants and carcasses are now routine outcomes of aerial surveys conducted to MIKE standards (Craig, 2012), and our method of determining the population trends by combining survey estimates for elephants and carcasses can be applied to any population with a time series of estimates for live and dead elephants.

The elephant population in Niassa is still the largest in Mozambique. Controlling poaching is complicated by the size of the Reserve and its difficult terrain, limited manpower and financial resources, human settlements within the Reserve, the long and porous international border with Tanzania, and weak national policy and legislation that do not facilitate substantial benefits for local communities. These factors combine to fuel the illegal ivory trade (van der Westhuizen, 2011). Poachers focus on big trophy bulls (Kambako Safaris, pers. comm.), the loss of which affects the viability of the safari industry and thus the management budget for the Reserve.

Management authorities in Niassa must deal with a district-driven rural development agenda on one hand and a conservation agenda on the other. The people living within the Reserve see little value in elephants and thus passively encourage poaching, which brings benefits through income, meat and the removal of potential human-elephant conflict. Reversing this attitude requires the conservation authorities to adopt strategies that give greater benefits to local communities from wildlife, and introduce livelihood strategies that stem vegetation clearance for the expansion of agriculture.

\section{Acknowledgements}

We thank Anabela Rodrigues, former Director of SGDRN, for providing access to the Niassa National Reserve aerial survey and law enforcement databases. This analysis is based on the findings of surveys conducted by Colin Craig and Debbie Gibson under contract to SGDRN. Those surveys were funded by USAID, the U.S. Fish and Wildlife Service, and Fauna \& Flora International. We also thank the safari operators and SGDRN field staff who provided observations on carcass decomposition. Fay Robertson and
Peter Frost commented on drafts of this article, and Peter also provided valuable discussion about MODIS fire data.

\section{References}

Baldus, R.D. \& Hahn, R. (2009) The Selous-Niassa Wildlife Corridor in Tanzania: Biodiversity Conservation from the Grassroots. Practical Experiences and Lessons from Integrating Local Communities into Trans-boundary Natural Resources Management. FAO, Rome, Italy, and CIC, Budapest, Hungary.

Burn, R.W., Underwood, F.M. \& Blanc, J. (2011) Global trends and factors associated with the illegal killing of elephants: a hierarchical Bayesian analysis of carcass encounter data. PLoS ONE, 6(9), e24165. CITES (2004) Monitoring of Illegal Hunting in Elephant Range States. A report to the 13th meeting of the Conference of the Parties to CITES. CoP 13 Doc. 29.3. CITES Secretariat, Geneva, Switzerland. CITES (2012) Elephant Conservation, Illegal Killing and Ivory Trade. Supplementary Information on Document SC62 Doc 46.1. A report to the 62nd meeting of the Standing Committee of CITES. SC62 Inf. 1. CITES Secretariat, Geneva, Switzerland.

Corfield, T.F. (1973) Elephant mortality in Tsavo National Park, Kenya. African Journal of Ecology, 11, 339-368.

Craig, G.C. (2006) Aerial Survey of Wildlife in the Niassa Reserve and Surrounds, Mozambique, October 2006. Sociedade para a Gestão e Desenvolvimento da Reserva do Niassa, Maputo, Mozambique.

Craig, G.C. (2009) Aerial Survey of Wildlife in the Niassa Reserve and Adjacent Areas, Mozambique, October 2009. Sociedade para a Gestão e Desenvolvimento da Reserva do Niassa, Maputo, Mozambique.

Craig, G.C. (2011) Aerial Survey of Wildlife in the Niassa Game Reserve, Mozambique, October 2011. Sociedade para a Gestão e Desenvolvimento da Reserva do Niassa, Maputo, Mozambique.

Craig, G.C. (2012) Monitoring the Illegal Killing of Elephants: Aerial Survey Standards for the MIKE Programme. Version 2.o. CITES MIKE Programme, Nairobi, Kenya.

Craig, G.C. \& Gibson, D.St.C. (2002) Aerial Survey of Wildlife in the Niassa Reserve and Hunting Concessions, Moçambique, October 2002. Sociedade para a Gestão e Desenvolvimento da Reserva do Niassa, Maputo, Mozambique.

Craig, G.C. \& Gibson, D.St.C. (2004) Aerial Survey of Wildlife in the Niassa Reserve and Surrounds, Mozambique, October 2004. Sociedade para a Gestão e Desenvolvimento da Reserva do Niassa, Maputo, Mozambique.

Cunliffe, R., Mandondo, A., Games, I., Ngarivhume, J. \& Doré, D. (2009) Reconciling Conservation Goals with Agriculturally Based Livelihoods: A Proposal for Future Development of the Niassa National Reserve and Surrounding Areas. Main Report (Volumes I \& II). Shanduko, Centre for Agrarian and Environmental Research, Harare, Zimbabwe, on behalf of: República De Moçambique, Província De Niassa; Fauna \& Flora International, Cambridge, England; and Sociedade Para a Gestão e Desenvolvimento Da Reserva Do Niassa, Maputo, Mozambique.

Douglas-Hamilton, I. \& Burrill, A. (1991) Using elephant carcass ratios to determine population trends. In African Wildlife: Research and Management (eds F.I.B. Kayanja \& E.L. Edroma), pp. 98-105. International Council of Scientific Unions, Paris, France.

Douglas-Hamilton, I. \& Hillman, A.K.K. (1981) Elephant carcasses and skeletons as indicators of population trends. In Low Level Aerial Survey Techniques. Report of an International Workshop, 6-11 November 1981, Nairobi, pp. 113-129. International Livestock Centre for Africa, Addis Ababa, Ethiopia. 
Dunham, K.M. (2008) Detection of anthropogenic mortality in elephant Loxodonta africana populations: a long-term case study from the Sebungwe region of Zimbabwe. Oryx, 42, 36-48.

FEWS NET (2014) Http://earlywarning.usgs.gov/fews/downloads/ index.php?regionID=af\&product ID $=3$ \&periodID $=6$ [accessed 4 August 2014].

Frontline Systems (2014) Basic Solver-Non-Smooth Optimization. Http://www.solver.com/content/basic-solver-non-smoothoptimization [accessed 12 February 2014].

Gasaway, W.C., DuBois, S.D., Reed, D.J. \& Harbo, S.J. (1986) Estimating moose population parameters from aerial surveys. Biological Papers of the University of Alaska, 22, 1-108. Http://winfonet.alaska.gov/sandi/moose/surveys/documents/ ua_biology_papers_nr_22.pdf [accessed 5 August 2014].

Gibson, D.St.C. (1998) Aerial Survey of Wildlife In and Around Niassa Game Reserve, Moçambique, October 1998. Sociedade para a Gestão e Desenvolvimento da Reserva do Niassa, Maputo, Mozambique.

Gibson, D.St.C. (2000) Aerial Survey of Wildlife in the Niassa Reserve and Hunting Concessions, Moçambique, October/November 2000.

Sociedade para a Gestão e Desenvolvimento da Reserva do Niassa, Maputo, Mozambique.

Herman, A., Kumar, V.B., Arkin, P.A. \& Kousky, J.V. (1997) Objectively determined 10-day African rainfall estimates created for famine early warning systems. International Journal of Remote Sensing, 18, 2147-2159.

Hofer, H. \& Mpanduji, D.G. (2004) Distribution and Movements of Elephants and Other Wildlife in the Selous-Niassa Wildlife Corridor, Tanzania. Tropical Ecology Support Programme. Deutsche Gesellschaft fur Technische Zusammenarbeit (GTZ) GmbH, Eschborn, Germany.

JolLy, G.M. (1969) Sampling methods for aerial censuses of wildlife populations. East African Agriculture and Forestry Journal, 34, 46-49.

Mandondo, A. \& Ngarivhume, J. (2009) Reconciling Conservation Objectives with Agriculturally Based Livelihoods in the Niassa National Reserve: Mobility, Settlement, Infrastructure, Markets, Livelihoods and Institutions. Annex 5. Shanduko, Centre for Agrarian and Environmental Research, Harare, Zimbabwe, on behalf of: República De Moçambique, Província De Niassa; Fauna \& Flora International, Cambridge, England; and Sociedade Para a Gestão e Desenvolvimento Da Reserva Do Niassa, Maputo, Mozambique.

Martin, R.B. (1992) Maximum likelihood analysis of the elephant population estimates for Matabeleland North, Zimbabwe. In Elephant Management in Zimbabwe, 2nd edition (eds R.B. Martin,
G.C. Craig \& V.R. Booth), pp. 87-91. Department of National Parks and Wildlife Management, Harare, Zimbabwe.

Marufo, M., Jorge, A. \& Rodrigues, A. (2009) Characteristics and Experiences of Human-Wildlife Conflict. Niassa National Reserve. Internal report prepared by Sociedade para a Gestão e Desenvolvimento da Reserva do Niassa, Maputo, Mozambique.

MODIS. Active Fire \& Burned Area Products. Http://modis-fire.umd. edu/index.html [accessed 4 August 2014].

Norton-Griffiths, M. (1978) Counting Animals, 2nd edition. African Wildlife Leadership Foundation, Nairobi, Kenya.

Ribeiro, N.S., Shugart, H.H. \& Washington-Allen, R. (2008) The effects of fire and elephants on species composition and structure of the Niassa Reserve, northern Mozambique. Forest Ecology and Management, 255, 1626-1636.

SGDRN (2006) Zoning management. In Niassa National Reserve Management Plan, Part II: Management Framework and Action Plan. Ministry of Tourism and Sociedade para a Gestão e Desenvolvimento da Reserva do Niassa, Maputo, Mozambique.

Snedecor, G.W. \& Cochran, W.G. (1980) Statistical Methods, 7th edition. Iowa State University Press, Ames, USA.

UNEP, CITES, IUCN \& TRAFFIC (2013) Elephants in the DustThe African Elephant Crisis. A Rapid Response Assessment. United Nations Environment Programme, GRID-Arendal, Arendal, Norway.

van Aarde, R., Otт, T., Ntumi, C. \& Trimble, M. (2009) Conflict Between People and Elephant-Zonation as a Potential Solution. Presentation at International Seminar on the Mitigation of HumanWildlife Conflict, 7-8 May 2009, Lichinga. Direcção Nacional de Terra e Florestas, Ministry of Agriculture, Maputo, Mozambique. VAn Der Westhuizen, H.F. (2011) Review: Law Enforcement Programme Niassa National Reserve. Internal report prepared for Sociedade para a Gestão e Desenvolvimento da Reserva do Niassa, Maputo, Mozambique.

Wells, M.P. (1989) The use of carcass data in the study and management of African elephants: a modelling approach. African Journal of Ecology, 27, 95-110.

\section{Biographical sketches}

VERNON BOоTH is a freelance wildlife management consultant with particular experience in administration and economics of the tourism industry, protected area management planning, natural resource project evaluation and appraisal, and community-based natural resource management. Kevin Dunham is a wildlife biologist interested in the management and conservation of large mammals. 